\title{
Effects of average velocity on the growth and surface topography of biofilms attached to the reclaimed wastewater drip irrigation system laterals
}

\author{
Gui Bing Li • Yun Kai Li • Ting Wu Xu • \\ Yao Ze Liu • Hai Jin • Pei Ling Yang • \\ Da Zhuang Yan $\cdot$ Shu Mei Ren $\cdot$ Zhi Fang Tian
}

Received: 6 March 2010/ Accepted: 20 January 2011 / Published online: 11 February 2011

(C) Springer-Verlag 2011

\begin{abstract}
Emitter clogging, a phenomenon commonly seen in reclaimed wastewater drip irrigation systems, is a severe obstacle to the wide applications and popularization of the irrigation technology. Some experiments showed that the emitter clogging was tightly related to biofilms formation attached to the irrigation system. In this paper, two types of wastewaters reclaimed respectively by fluidizedbed reactor (FBR) process and biological aerated filter (BAF) process were chosen as the experiment objects and
\end{abstract}

The authors G. B. Li, Y. K. Li, and T. W. Xu equally contributed to this paper.

Communicated by $\mathrm{T}$. Trooien.

G. B. Li · Y. K. Li (ه) - Y. Z. Liu · P. L. Yang ·

D. Z. Yan $\cdot$ S. M. Ren $(\bowtie) \cdot$ Z. F. Tian

Center for Agricultural Water Research in China,

China Agricultural University, 100083 Beijing, China

e-mail: liyunkai@126.com

S. M. Ren

e-mail: renshumei@126.com

Y. K. Li

State Key Laboratory of Urban and Regional Ecology,

Research Center for Eco-Environmental Sciences,

Chinese Academy of Sciences, 100085 Beijing, China

G. B. Li

HYDROCHINA Beijing Engineering Corporation,

100024 Beijing, China

T. W. Xu

International College at Beijing, China Agricultural University, 100083 Beijing, China

H. Jin

School of Sciences, Beijing Institute of Technology,

Beijing 100081, China then the effects of the average velocity on the growth and topography of biofilms attached to the irrigation laterals were studied. The parameters of biofilms reached their maximal values at a critical velocity of $0.45 \mathrm{~m} / \mathrm{s}$. The formation of biofilms was primarily controlled by the transport of the nutrients and suspended particles within the laterals when the average velocity is below the critical velocity, whereas it was primarily controlled by the hydraulic shear force when above the critical velocity. The main mechanism for emitter clogging was that the biofilms detached from laterals accumulated and grew at the inlets and outlets of emitters. A similar variation pattern was observed for both reclaimed wastewaters. However, the growth of biofilms for BAF process was more affected by the shear force than that for FBR process, since the nutrients and suspended particles for BAF were larger than those for FBR.

\section{Introduction}

An emitter is a key part of a drip irrigation system. The flow path of emitter is extremely narrow, and hence, easily clogged by pollutants like suspended particles, chemical deposits, and microorganisms. Under some circumstance, it would make the irrigation system unusable (Dasberg and Or 1999; Li et al. 2006). Emitter clogging has become the key problem to the applications and popularization of the drip irrigation technology. After the first international conference on drip irrigation (held in Israel in 1971), many researchers tried to solve the clogging problem by rational installation of filtering equipment, periodical acids and chlorine treatment, and optimal design of labyrinth flow path (Adin and Sacks 1991; Avnimelech 1993; Ravina et al. 1992, 1997; Li et al. 2008). The problem, however, has not been well solved. The reason is that the mechanism of clogging is not clearly understood. 
Reclaimed wastewater irrigation was one of the effective approaches to alleviating the global water resources shortage (Asano et al. 2007). Drip irrigation was regarded as the most effective and reliable pattern for reclaimed wastewater irrigation (Adin and Sacks 1991; Capra and Scicolone 2004, 2005; Ravina et al. 1992, 1997; Liu and Huang 2009). Currently, almost all researches indicated that the irrigation water quality plays an important role in emitter clogging. The constituents of reclaimed wastewaters are suspended particles, salinity ions, and organisms and microbial community (Asano et al. 2007; Li et al. 2006) clog emitters (Rowan et al. 2004). Independent researches showed that the emitter clogging of drip irrigation with reclaimed wastewaters was tightly related to the formation and growth of biofilms (Adin and Sacks 1991; Capra and Scicolone 2004, 2005; Liu and Huang 2009; Ravina et al. 1992, 1997). Although the conformation and structures of biofilms have attracted the attentions from the fields of water pollution and control (Bishop 2007; Chen 2007; Qin 2008), there were few research results on the biofilms attached to the irrigation systems. The existing relevant research outcomes had been based on the supply pipe (Gouidera et al. 2009; Lehtola et al. 2006; Simpson 2008). The nutrients, organic substances, and trace elements contained in the reclaimed water after secondary or even tertiary treatment could sustain the growth of microorganisms. The formation process of the biofilms was a comprehensive reaction of the attachment, growth, detachment, and decay of microorganisms (Chen 2007). There were two types of biofilm detachments. One was caused by the reduction in biofilms viscosity force due to the reduction in secretive exopolysaccharide (EPS). The reductions in EPS lead to the restrained nutrient transmission and reproduction requirement of new microorganisms. The other was caused by external forces. The kinetic parameters of the flow, such as velocity, turbulence intensity, Reynolds number, and hydraulic shear force, had significant effects on the growth and detachment of the biofilms. Research reports on whether the biofilms and deposits within the emitter come from the self-growth or detachment from drip irrigation laterals were rarely seen. Research reports on the biofilms characteristics and their response mechanisms considering both nutrient transport and hydraulic shear force were hard to find.

The morphology characteristics of biofilms included the properties of the roughness, thickness, and pore ratio. They were the comprehensive expression under the common effects of the hydraulic power, water quality, temperature, etc. (Qin 2008). In this paper, two types of wastewaters reclaimed respectively by the widely used FBR and BAF processes were chosen as the experiment objects, the effects of average velocity on the 3D profilometry and growth characteristics of biofilms attached to the reclaimed wastewater drip irrigation laterals were studied, and simulations of reclaimed wastewater drip irrigation under indoor constant temperatures were conducted. The response mechanism of the biofilms to the fluid movement was analyzed. The objective of this study is to provide the theoretical reference for the mechanisms of the emitter clogging and for the control model under reclaimed wastewater drip irrigation.

\section{Materials and methods}

\section{Experimental materials}

The experiment was conducted in Yanqihu Wastewater Treatment Plant in Huairou District, Beijing. The plant was one of the demonstrative plants in China. The two kinds of reclaimed wastewaters studied in the paper were generated by the plant, which separately adopts the process of BAF and FBR. The detailed wastewater treatment procedure can be found in $\mathrm{Li}$ et al. (2010). The irrigation water quality indices were shown in Table 1.

\section{Experiment design}

The experiment focused on the effects of the velocity in the drip irrigation laterals on the biofilms, while ignoring the influence on the local flow by the emitter. The laterals were substituted by the PE pipelines with the outside diameter $16 \mathrm{~mm}$ (inside diameter $13.8 \mathrm{~mm}$ ). The experiment selected 6 levels of the common velocities, head loss, and inlet pressure in the laterals, which was shown in Tables 2 and 3 . The flow velocity was determined by quantity of water flow at the end of drip irrigation pipes with measuring cylinder for $3 \mathrm{~min}$. In the experimental process, to ensure the velocity on every pipe is invariant, measuring cylinder was used to measure water discharge about every 2 days. At the same time, the pressure gauge was read. Because the thickness of biofilms was small (about umpty umpth micrometers), while the diameter of PE pipes was over ten

Table 1 Water quality parameters of two reclaimed wastewaters

\begin{tabular}{lcclll}
\hline Parameters & BAF & FBR & Parameters & BAF & FBR \\
\hline $\mathrm{COD}$ & 50 & 33 & $\mathrm{pH}$ & 7.26 & 7.31 \\
$\mathrm{SS}(\mathrm{mg} / \mathrm{l})$ & 12.5 & 25 & $\mathrm{TSS}(\mathrm{mg} / \mathrm{L})$ & 24 & 78 \\
$\mathrm{NH}_{3}-\mathrm{N}$ & 0.33 & 0.8 & $\mathrm{Ca}^{2+}(\mathrm{mg} / \mathrm{L})$ & 68.7 & 65.8 \\
$\mathrm{NO}_{2}-\mathrm{N}$ & 0.3 & 1 & $\mathrm{Mg}^{2+}(\mathrm{mg} / \mathrm{L})$ & 10.9 & 6.93 \\
$\mathrm{NO}_{3}-\mathrm{N}$ & 0.5 & 2 & $\mathrm{Fe}^{3+}(\mathrm{mg} / \mathrm{L})$ & 0.15 & 0.41 \\
$\mathrm{TN}(\mathrm{mg} / \mathrm{L})$ & 7.02 & 7.06 & $\mathrm{Mn}^{2+}(\mathrm{mg} / \mathrm{L})$ & 0.01 & 0.11 \\
$\mathrm{TP}(\mathrm{mg} / \mathrm{L})$ & 1.91 & 2.18 & Ionicity $\left(\mathrm{us} / \mathrm{cm} 23^{\circ} \mathrm{C}\right)$ & 471 & 505 \\
$\mathrm{DO}(\mathrm{mg} / \mathrm{l})$ & 3.97 & 1.21 & - & & \\
\hline
\end{tabular}


Table 2 Experiment treatments

\begin{tabular}{llllll}
\hline $\begin{array}{l}\text { Experiment } \\
\text { treatments }\end{array}$ & $\begin{array}{l}\text { Average } \\
\text { discharge } \\
q\left(\mathrm{~m}^{3} / \mathrm{s}\right)\end{array}$ & $\begin{array}{l}\text { Average } \\
\text { velocity } \\
v(\mathrm{~m} / \mathrm{s})\end{array}$ & $\begin{array}{l}\text { Hydraulic } \\
\text { shear } \\
\tau\left(\mathrm{N} / \mathrm{m}^{2}\right)\end{array}$ & $\begin{array}{l}\text { Reynolds } \\
\text { number } \\
R e\end{array}$ & $\begin{array}{l}\text { Regimen of } \\
\text { PE pipe flow }\end{array}$ \\
\hline $\mathrm{T}_{1}$ & 0.03 & 0.06 & 0.31 & 916 & Laminar fluid \\
$\mathrm{T}_{2}$ & 0.06 & 0.12 & 0.63 & 1,834 & Laminar fluid \\
$\mathrm{T}_{3}$ & 0.24 & 0.45 & 0.81 & 7,334 & Turbulent fluid \\
$\mathrm{T}_{4}$ & 0.48 & 0.90 & 2.73 & 14,670 & Turbulent fluid \\
$\mathrm{T}_{5}$ & 0.72 & 1.34 & 5.84 & 22,004 & Turbulent fluid \\
$\mathrm{T}_{6}$ & 0.96 & 1.78 & 8.71 & 29,340 & Turbulent fluid \\
\hline
\end{tabular}

Table 3 Head loss and values of pressure in lateral

\begin{tabular}{llcl}
\hline $\begin{array}{l}\text { Experiment } \\
\text { treatments }\end{array}$ & $\begin{array}{l}\text { Average } \\
\text { velocity } v(\mathrm{~m} / \mathrm{s})\end{array}$ & $\begin{array}{l}\text { Lateral head } \\
\text { loss } h_{\mathrm{f}}(\mathrm{cm})\end{array}$ & $\begin{array}{l}\text { Values of inlet } \\
\text { pressure in lateral } P(\mathrm{~m})\end{array}$ \\
\hline $\mathrm{T}_{1}$ & 0.06 & 0.23 & 10.00 \\
$\mathrm{~T}_{2}$ & 0.12 & 0.46 & 9.99 \\
$\mathrm{~T}_{3}$ & 0.45 & 6.78 & 9.92 \\
$\mathrm{~T}_{4}$ & 0.90 & 24.04 & 9.72 \\
$\mathrm{~T}_{5}$ & 1.34 & 47.95 & 9.43 \\
$\mathrm{~T}_{6}$ & 1.78 & 83.54 & 9.00 \\
\hline
\end{tabular}

millimeters, the affection of the adding thickness of biofilm on the flow velocity was not considered. Only the affection of flow in the pipes on the formation of biofilm was analyzed. The hydraulic shear stress in the pipes is calculated by the following formula (Dasberg and Or 1999):

$\tau=\frac{\lambda}{8} \rho v^{2}$

$\lambda= \begin{cases}64 / R_{e} & \left(R_{e}<2320\right) \\ 0.3164 / R_{e}^{0.25} & \left(R_{e}>2320\right)\end{cases}$

where $\lambda$ is the pipeline friction factor of head loss, $\rho\left(\mathrm{kg} / \mathrm{m}^{3}\right)$ is the density of water with a typical value of $1.0 \times 10^{-3}$. $v(\mathrm{~m} / \mathrm{s})$ is the velocity; $R e$ is the Reynolds number; $\tau(N)$ is the water power shearing force. Five replacements of each treatment were used for biofilms sampling, which is the need for destructive sampling. A pipeline is destroyed in every sampling, so the same position for every sampling is ensured.

The velocity in the pipes was regulated by controlling the discharge in the pipes. Refer to Fig. 1 for the setting of the experiment system. The pressure-adjusting valve (12) was used for the rough regulation of the controlling pressure, and the microregulation of pressure was realized by joint usage of pressure-adjusting valves (8) and (11). The 3-level pressure regulation can produce a stable target outflow discharge. The system was open at 8:00 am every day and closed after $8 \mathrm{~h}$ of operation. The system was closed for 1 day after it had been operated for 4 days. The water temperatures were measured at noon every day and they were in the range of $28.0 \pm 1.5^{\circ} \mathrm{C}$ during the experiment period. The difference in temperature was relatively small, and the error caused by temperature difference was ignored.

Biofilms sampling and testing methods

After the operation of the system, a length of 2-5 cm of every pipe was periodically cut from the middle and put into the label bag for biofilms testing on every replication. Five samples were taken during the experiment. The time for sampling was no. 9 day $(72 \mathrm{~h})$, no. 15 day $(120 \mathrm{~h})$, no. 20 day $(160 \mathrm{~h})$, no. 25 day $(200 \mathrm{~h})$, and no. 27 day (216 h). Two samples were picked for the first sampling. One was for the observation of the biofilms topography during the initial stage, and the other was for the thickness measurement of the biofilms growth. For each of the rest sampling schemes, only one sample was taken for the thickness measurement. The average of the five thickness measurements was regarded as the thickness for the given condition. The biofilms form an open-ended, self-organizing microbiological system. The "S-curve" function can be used to simulate the biofilms growth process, which is given as follows

$y=e^{\left(b_{0}+b_{1} / t\right)}$

where $y$ denotes the average biofilms thickness, $t$ denotes the operation time, and $b_{0}$ and $b_{1}$ are undetermined parameters.

The microscope of type JNOEC XS-2121 was used for the measurement of biofilms thickness. The highlight halide torch of $220 \mathrm{~V} / 60 \mathrm{~W}$ was used as the light source. The biofilms topography analysis was conducted with the 


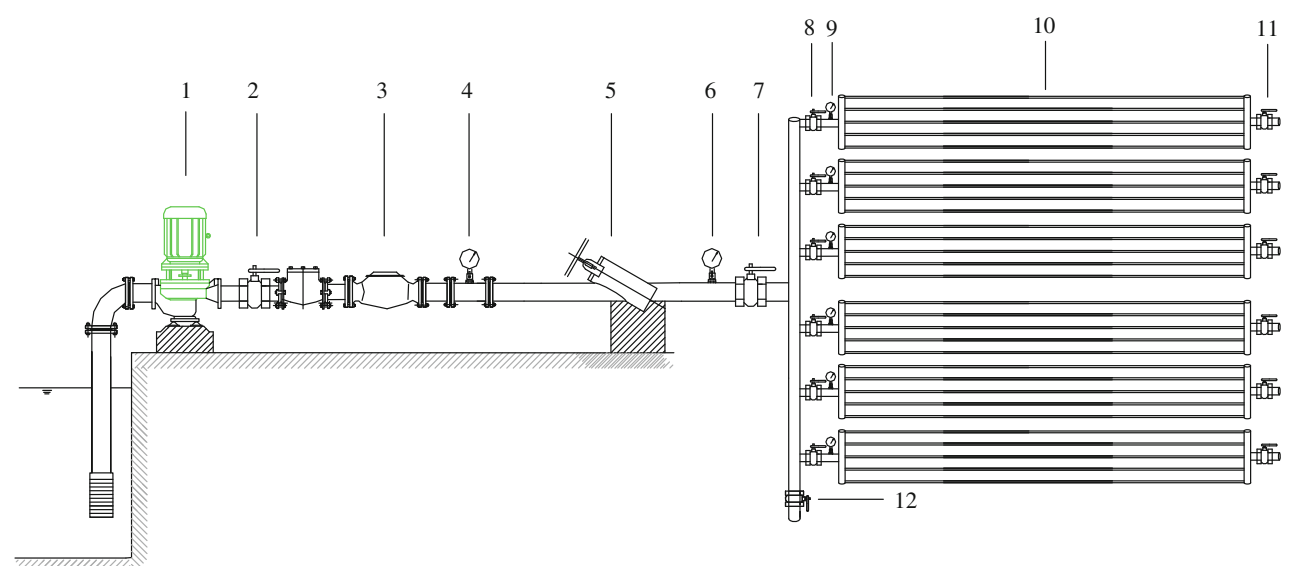

1. Pump 2. 7. 8.11. 12. Gate valve 3. Water meter 4.6.9 Manometer 5. Filter(120 mesh screen filter) 10. Drip irrigation lateral

Fig. 1 Experiment setting

vertical scanning white-light interference profilometer (type: Micro-XPM) manufactured by ADE. The sample size was $0.3 \mathrm{~cm} \times 0.3 \mathrm{~cm}$. The objective lens was $50 \times$, and the testing scope was a $128 \times 173 \mu \mathrm{m}$ rectangular region.

Evaluation index of biofilm 3D surface topography

SPIP software was used to analyze the images collected by the $3 \mathrm{D}$ white-light interference profilometer. The three parameters of surface topography were $R_{a}$ (roughness average), $S_{y}$ (peak height), and $S_{d r}$ (area ratio of extended surface to projecting plane). They were calculated as follows:

\section{Roughness $S_{q}$}

Roughness was the square root of the average height of contour offset distance. Formula (4) shows its calculation.

$S_{q}=\sqrt{\frac{1}{M N} \sum_{k=0}^{M-1} \sum_{l=0}^{N-1}\left[z\left(x_{k}, y_{l}\right)-\mu\right]^{2}}$

where $M$ denotes no. of $M$ horizontal unit of the region, $N$ denotes no. of $N$ vertical unit, $x_{k}$ denotes no. of $\mathrm{K}$ horizontal unit, and $y_{l}$ denotes no. of $L$ vertical unit. The unit of $S_{q}$ is nm. $Z\left(x_{k}, y_{l}\right)(\mathrm{nm})$ denotes the height corresponding to no. of $K$ horizontal and no. of $L$ vertical unit of the region, and $\mu(\mathrm{nm})$ denotes the average height and can be calculated using formula (5):

$\mu=\frac{1}{M N} \sum_{k=0}^{M-1} \sum_{l=0}^{N-1} z\left(x_{k}, y_{l}\right)$

2. Peak height $S_{y}$

$S_{y}=Z_{\max }-Z_{\min }$ where $Z_{\max }(\mathrm{nm})$ and $Z_{\min }(\mathrm{nm})$ denote the highest and the lowest point in the sampling region, respectively.

3. Specific surface area $S_{d r}$

The specific surface area was the area ratio of extended surface to projecting plane, which is calculated as follows:

$S_{d r}=\frac{\left(\sum_{k=0}^{M-2} \sum_{l=0}^{N-2} A_{k l}\right)-(M-1)(N-1) \delta_{x} \delta_{y}}{(M-1)(N-1) \delta_{x} \delta_{y}} \times 100 \%$

$$
\begin{aligned}
A_{k l}=\frac{1}{4} & \left(\sqrt{\delta_{x}^{2}+\left(z\left(x_{k}, y_{l}\right)-z\left(x_{k}, y_{l+1}\right)\right)^{2}}\right. \\
& \left.+\sqrt{\delta_{y}^{2}+\left(z\left(x_{k+1}, y_{l}\right)-z\left(x_{k+1}, y_{l+1}\right)\right)^{2}}\right)
\end{aligned}
$$

where $\delta_{x}(\mathrm{~nm})$ and $\delta_{y}(\mathrm{~nm})$ denote the pixel distances along $x$ - and $y$-axis, respectively. $S_{d r}$ is dimensionless, whereas the unit of $A_{k l}$ is $\mathrm{nm}^{2}$.

\section{Results and analyses}

Growth properties of biofilms attached to laterals

Figure 2 showed the results for the average thickness of biofilms in laterals over time. It could be found that the biofilms would attach to the internal walls of laterals with different thicknesses. There was a common growth process of biofilms under six velocities: initial quick growth, gradual stability, and final fluctuant equilibrium. But there were some obvious differences among the six velocities. During the initial fast-growth stage (0-9 days), the biofilms thickness increased linearly and the biofilms accumulated. 


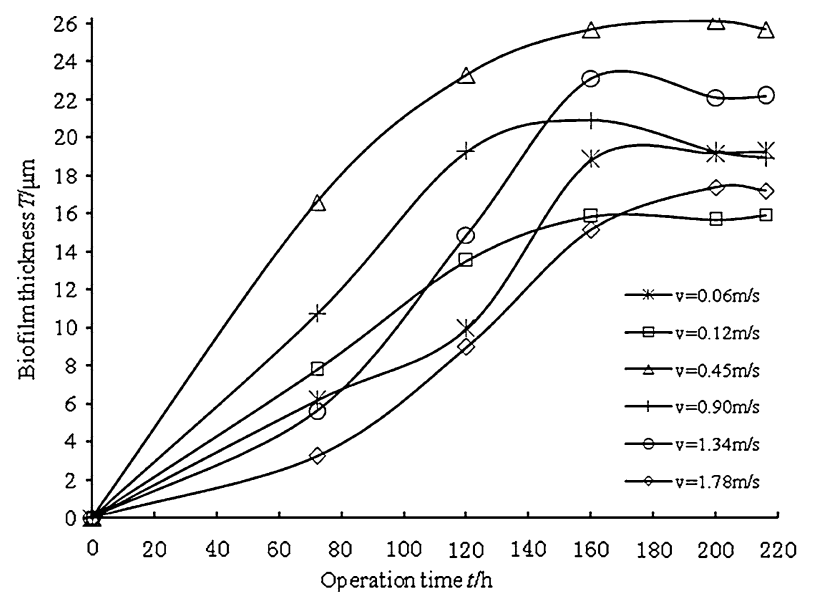

(a)

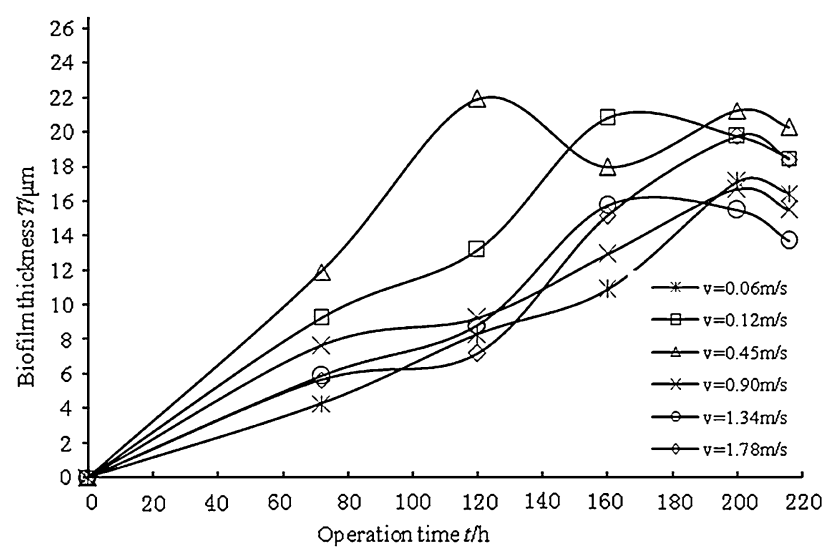

(b)

Fig. 2 Biofilms thickness attached to two reclaimed wastewater laterals under different velocities. a FBR, b BAF

During the later period (15-27 days), the biofilms grew slowly and its thickness fluctuated because there was a dynamic procedure of growth, detachment, and re-growth. The fluctuation for BAF is stronger than that of FBR; the biofilms thickness for BAF was thinner than that of FBR; and the maximum average thicknesses of the two reclaimed wastewaters were, respectively, 15.8-21.2 and $17.4-26.1 \mu \mathrm{m}$ after $160 \mathrm{~h}$. The time for the biofilms thickness in the two wastewaters to reach homeostasis under six velocities was different. With increasing average velocities, the time for reaching homeostasis of biofilms thickness decreased first and then increased. The time required for the stability in the region of biofilms was the shortest at velocity $0.90 \mathrm{~m} / \mathrm{s}$. The biofilm was an openended self-organizing microbiological system. Table 4 showed the simulated results of biofilms growth process by using the "S-curve". The biofilms growth in laterals supplying two reclaimed wastewaters possessed a change of S-curve $\left(R^{2}\right.$ is greater than 0.81). However, there was a better fitting for FBR.
Relationship between average velocity and thickness of biofilms during the fast-growth stage

When the operation time of the system was shorter than $120 \mathrm{~h}$, the biofilms growth was in the fast stage. Figure 2 showed the thickness of biofilms attached to laterals under six different velocities. The microscope was applied to measure the average thickness of the biofilms during the fast-growth period (72 and $120 \mathrm{~h}$ ). Figure 3 showed the results between biofilms thickness and the flow velocity. There was a unimodal type of relationship between them. The average biofilms thickness reached its maximum at velocity $0.45 \mathrm{~m} / \mathrm{s}$ during the fast-growth period, which implied that the biofilm was most easily to be formed at the velocity. For reclaimed wastewater by FBR with velocity greater than $0.12 \mathrm{~m} / \mathrm{s}$, the relationship curves of the average biofilms thickness to velocity were parallel. The average thickness of biofilms was primarily controlled by the velocity and there was a linear change pattern. There was no similar relationship for BAF reclaimed wastewater, though.

Effects of average velocity on the 3D surface topography characteristics of biofilms during the fast-growth stage

During the fast-growth period up to $72 \mathrm{~h}$ of system operation, the 3D vertical scanning white-light interference profilometer was used to measure the thickness of biofilms attached to BAF and FBR reclaimed wastewater laterals. Refer to Figs. 4 and 5 for the results. The results indicated that the biofilms were not smooth but undulate. At the same time, the biofilms surface topography changed from smooth to rough with the increase in velocity. At velocities 0.06 and $0.12 \mathrm{~m} / \mathrm{s}$, the large local unimodal pimpling occurred on the biofilms surface; at 0.45 and $0.90 \mathrm{~m} / \mathrm{s}$, the biofilms surface was comparatively smooth with plenty of undulate dots, whereas at 1.34 and $1.70 \mathrm{~m} / \mathrm{s}$, the local concaves occurred on the biofilms surface.

The results of $S_{q}, S_{y}$, and $S_{d r}$ were shown in Table 5. The parameters $S_{q}$ and $S_{y}$ reflected the biofilms surface roughness. With increasing velocities for both reclaimed wastewaters, the two parameters increased initially and then decreased, which was similar to the result of 3D surface topography characteristic. $S_{d r}$ primarily measures the adsorption capacity of biofilms surface. Larger values of $S_{d r}$ lead to greater adhesive power of the biofilms surfaces to solid granules and more accumulation of the microbial community and microorganisms. With the increase in velocities, $S_{d r}$ also increased first and then decreased. Generally speaking, the values of $S_{q}, S_{y}$, and $S_{d r}$ were all relatively large at velocities 0.12 and $0.45 \mathrm{~m} / \mathrm{s}$. At these velocities, the biofilms surface was the roughest and most 
Table 4 Parameters of S-curve fitting for the growth process of biofilms

\begin{tabular}{|c|c|c|c|c|c|c|c|c|}
\hline \multirow[t]{2}{*}{ Velocity $(\mathrm{m} / \mathrm{s})$} & \multicolumn{4}{|c|}{ Reclaimed wastewater of FBR } & \multicolumn{4}{|c|}{ Reclaimed wastewater of BAF } \\
\hline & $b_{0}$ & $b_{1}$ & $R^{2}$ & $P$ & $b_{0}$ & $b_{1}$ & $R^{2}$ & $P$ \\
\hline 0.06 & 3.60 & -131.71 & 0.93 & 0.007 & 3.44 & -147.18 & 0.96 & 0.003 \\
\hline 0.12 & 3.19 & -79.10 & 0.96 & 0.004 & 3.40 & -85.64 & 0.90 & 0.014 \\
\hline 0.45 & 3.52 & -49.50 & 0.96 & 0.003 & 3.33 & -56.41 & 0.81 & 0.065 \\
\hline 0.90 & 3.35 & -65.09 & 0.82 & 0.035 & 3.11 & -82.88 & 0.87 & 0.021 \\
\hline 1.34 & 3.94 & -155.67 & 0.96 & 0.003 & 3.22 & -106.12 & 0.89 & 0.016 \\
\hline 1.78 & 3.78 & -187.09 & 0.99 & 0.000 & 3.60 & -131.71 & 0.85 & 0.027 \\
\hline
\end{tabular}

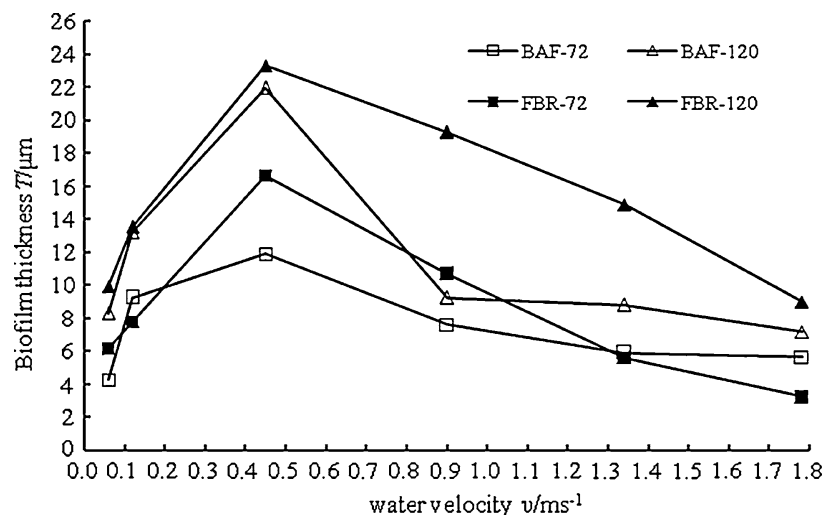

Fig. 3 Relationship between average velocity and biofilms thickness during the fast-growth period

adhesive. Comparatively speaking, the change tendency for BAF was stronger than that of FBR.

\section{Discussions}

The existence of emitter clogging was the bottleneck to restrain the application and popularization of reclaimed wastewater drip irrigation technology. A few researches indicated that the clogging of drip reclaimed wastewater irrigation system was tightly related to the formation and growth of biofilms (Adin and Sacks 1991; Capra and Scicolone 2004, 2005; Liu and Huang 2009; Ravina et al. 1992, 1997; Rowan et al. 2004; Yan et al. 2009).

Microorganisms like bacteria can attach to the surface of any solid in the water under natural environment. The water source commonly contained nutrients, such as inorganic salt, nitrogen, and phosphorus, especially for reclaimed wastewaters. The bacteria in water can attach to medium surfaces with plenty of nutrients for growth and reproduction. The living and dead bacteria, cell debris, and solid particles were usually packed by the thick EPS to form a 3D-heterostructural and functional entity, which is called biofilms. The biofilms formation process is a dynamic variation process that has different expressions in the process of attachment, growth, detachment, and decay, which leads to complex surface topography characteristics of biofilms (Simpson 2008). In this study, we discovered that the growth of biofilms attached within two reclaimed wastewater drip system laterals gradually reached homeostasis after the initial fast-growth stage. The reason was that during the initial growth period, there were more microorganisms and more viscid secretion, and the biofilms could easily absorb and capture solid particles and microbial groups so as to grow faster during the period. When the biofilms reached its limit thickness, there were competitions for nutrients with increasing microorganism quantity and viscid secretion. At the same time, with increasing biofilms thickness, the nutrient transmission within the biofilms system became difficult, which reduced the nutrient concentrations for biofilms inside. The lower nutrient concentrations killed internal microorganisms and reduced the metabolism. The viscid secretion produced by microorganisms reduced and the agglutinability and adhesion force of biofilms also reduced. Then, the biofilms detached due to external impacts by hydraulic shear forces, and the re-growth of biofilms continued. The process of growth-detachment-regrowth of biofilms made itself reach homeostasis after a certain period of time. The biofilms detached from drip irrigation pipe systems and then deposited in the emitter, which induces the emitter clogging.

The reclaimed wastewaters contain plenty of organisms, metal ions, suspended solid particles, and microorganism. The nutrients sustaining the growth of microorganisms, the microorganisms themselves, and solid particles could pass through the filters and enter the irrigation system, which provides the opportunity for the biofilms to grow. The detachment of biofilms was a natural process for the growth of microorganisms and was difficult to control. Restraining the growth of biofilms in drip irrigation system was the key to solving the problem of emitter clogging. There were many factors affecting the formation of biofilms on the media surface, including fluid dynamic behavior (velocity, turbidity and hydraulic shear force), nutrient and disinfectant concentrations, suspended 


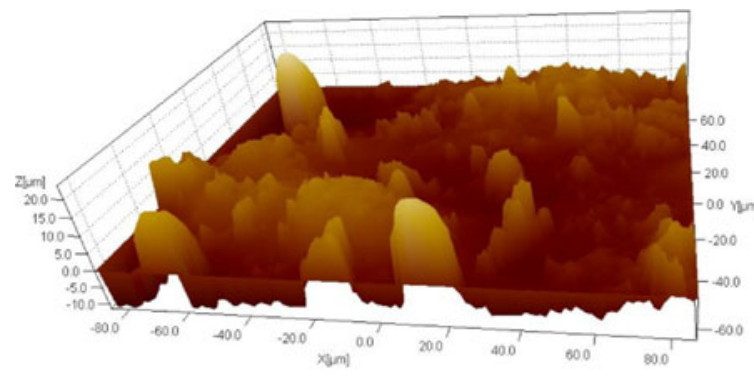

(a)

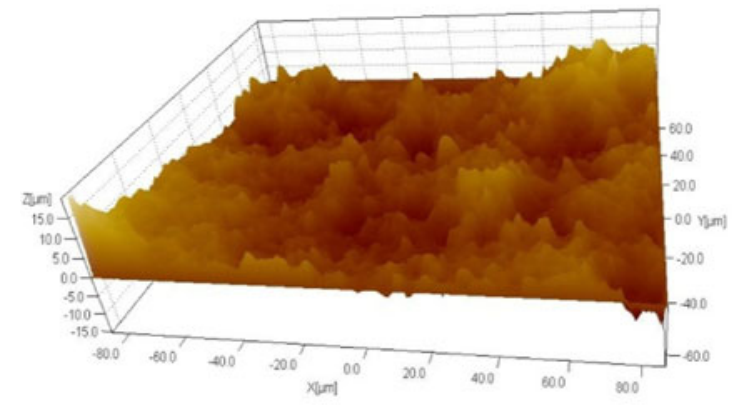

(c)

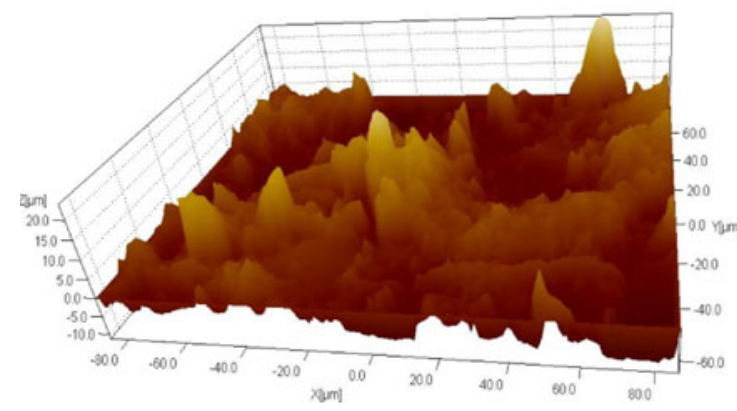

(e)

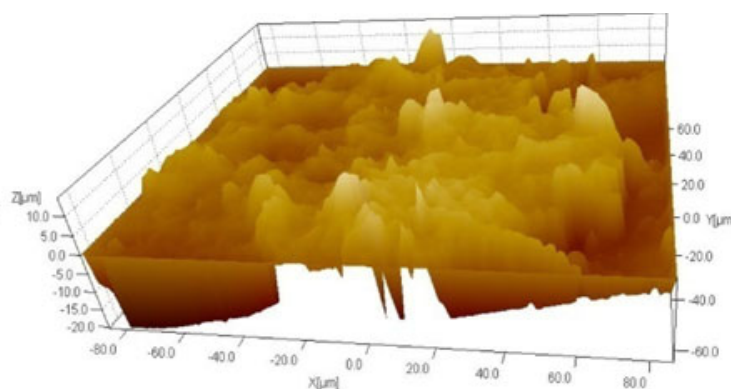

(b)

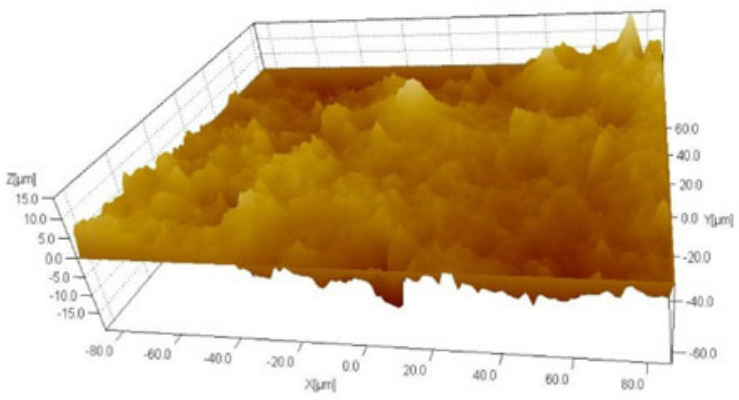

(d)

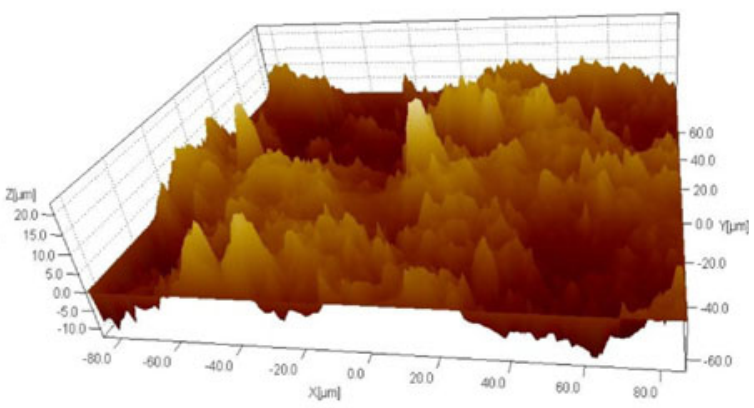

(f)

Fig. 4 3D surface topography characteristic images of biofilms attached to FBR reclaimed wastewater drip irrigation laterals. a $0.06 \mathrm{~m} / \mathrm{s}$, b $0.12 \mathrm{~m} / \mathrm{s}$, c $0.45 \mathrm{~m} / \mathrm{s}$, d $0.90 \mathrm{~m} / \mathrm{s}$, e $1.34 \mathrm{~m} / \mathrm{s}, \mathbf{f} 1.70 \mathrm{~m} / \mathrm{s}$

bacteria quantity, water temperature, and media material (Chen 2007; Gouidera et al. 2009; Manuel et al. 2007; Qin 2008; Simpson 2008). The water dynamic characteristics were one of the most influential factors. Ollos (1998) thought that with the increase in velocity, the number of bacteria in the biofilms increased. Cloete et al. (2003) discovered that the detachment of biofilms from the media surface was easy to occur when the velocity was 3-4 m/s. Lehtola et al. (2006) discovered that when the velocity was $0.03-0.19 \mathrm{~m} / \mathrm{s}$ in $\mathrm{PE}$ or copper pipes, the growth rate of biofilms and the bacteria increased progressively with the increase in velocity. Percival et al. (2001) discovered that the biofilm thickness with a velocity of $1.75 \mathrm{~m} / \mathrm{s}$ was thinner than those with velocities of 0.32 and $0.96 \mathrm{~m} / \mathrm{s}$. Chang et al. (1991) discovered that the increasing velocity significantly affects the detachment of biofilm and the detachment rate increased with the increase in turbidity. Nicolella et al. (1996) achieved the similar results. The early research by Rittmann (1982) showed that the detachment rate was proportional to the 0.58-th power of hydrodynamic shear force. However, Bakke et al. (1984) discovered that the detachment rate was linearly related to hydrodynamic shear force. Horn et al. (2003) thought that the detachment of biofilms was the joint result by hydrodynamic shear force and the intensity of biofilms. All the discoveries above showed that the fluid velocity affected the growth of biofilms by changing shear force, turbidity, and nutrient transport. The nutrient, organic substance, and trace element contained in the reclaimed water after its secondary treatment or even tertiary 


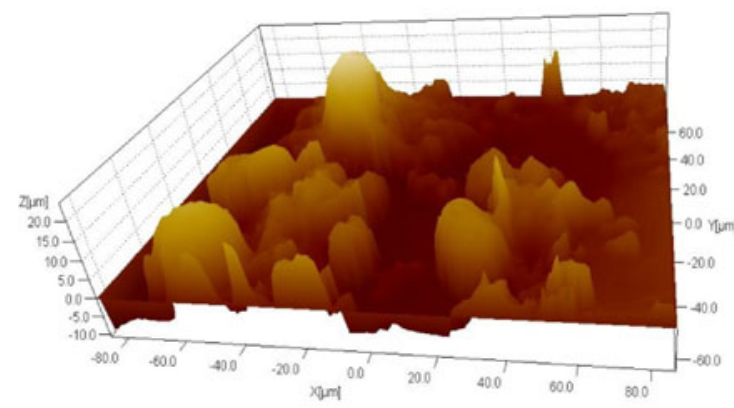

(a)

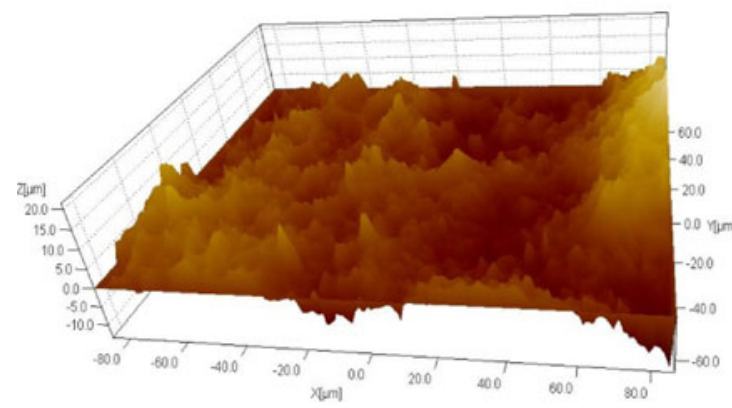

(c)

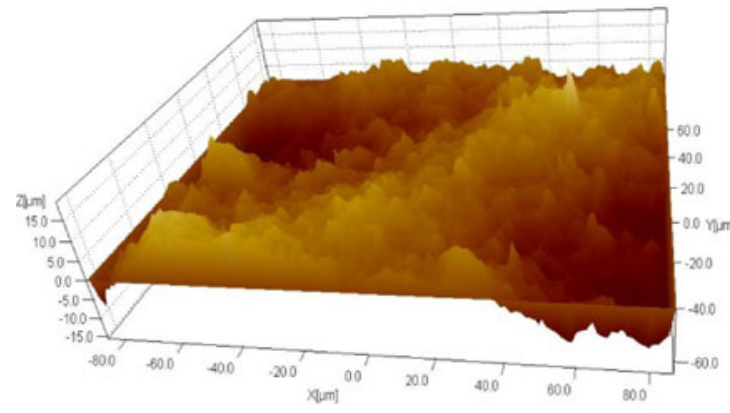

(e)

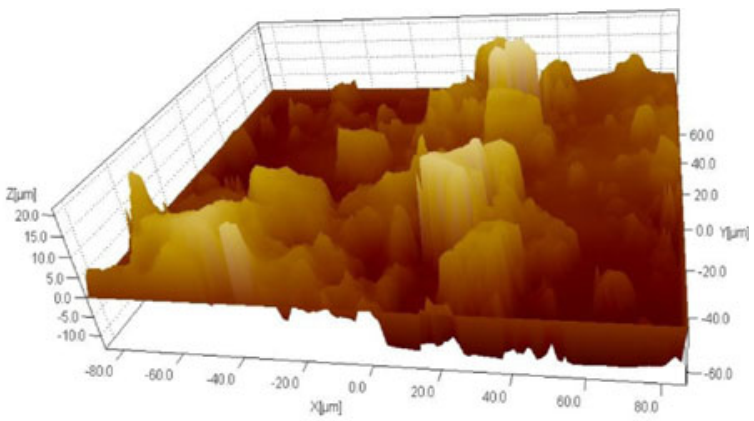

(b)

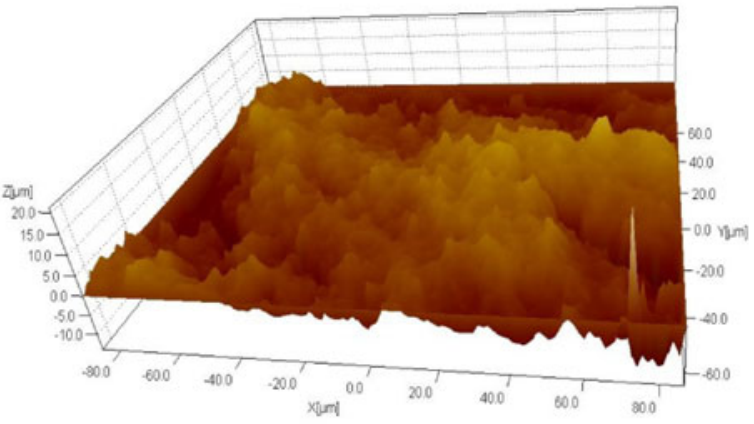

(d)

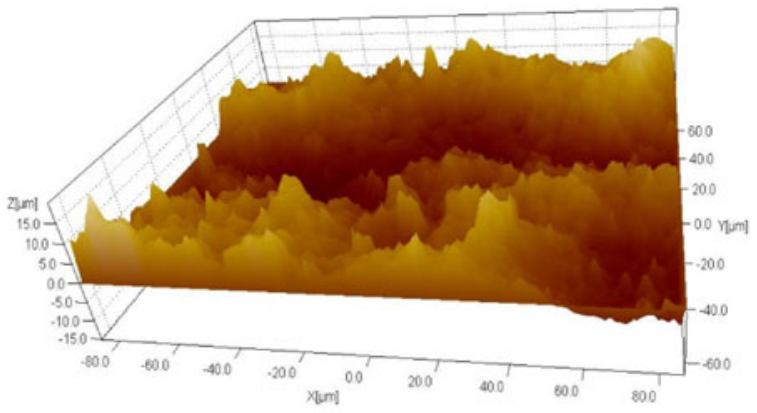

(f)

Fig. $53 \mathrm{D}$ surface topography characteristic images of biofilms attached to BAF reclaimed wastewater drip irrigation laterals. a $0.06 \mathrm{~m} / \mathrm{s}$, b $0.12 \mathrm{~m} / \mathrm{s}$, c $0.45 \mathrm{~m} / \mathrm{s}, \mathbf{d} 0.90 \mathrm{~m} / \mathrm{s}$, e $1.34 \mathrm{~m} / \mathrm{s}$ f $1.78 \mathrm{~m} / \mathrm{s}$

Table 5 Parameters of 3D surface topography characteristics under different velocities

\begin{tabular}{|c|c|c|c|c|c|c|c|}
\hline \multirow[t]{2}{*}{ WRQT } & \multirow[t]{2}{*}{ P3DST } & \multicolumn{6}{|c|}{ Velocity $\mathrm{v} /(\mathrm{m} / \mathrm{s})$} \\
\hline & & 0.06 & 0.12 & 0.45 & 0.90 & 1.34 & 1.78 \\
\hline \multirow[t]{3}{*}{ FBR } & $S_{\mathrm{q}}(\mathrm{nm})$ & 2,652 & 3,838 & 2,562 & 1,960 & 1,907 & 1,453 \\
\hline & $S_{\mathrm{y}}(\mathrm{nm})$ & 18,725 & 28,621 & 19,538 & 19,397 & 15,748 & 9,057 \\
\hline & $S_{\mathrm{dr}}(\%)$ & 28.60 & 49.30 & 32.20 & 18.00 & 16.10 & 9.78 \\
\hline \multirow[t]{3}{*}{ BAF } & $S_{\mathrm{q}}(\mathrm{nm})$ & 1,729 & 5,457 & 5,163 & 2,252 & 2,084 & 2,174 \\
\hline & $S_{\mathrm{y}}(\mathrm{nm})$ & 11,977 & 32,496 & 31,488 & 15,191 & 13,152 & 12,778 \\
\hline & $S_{\mathrm{dr}}(\%)$ & 10.3 & 94.3 & 27.6 & 18.4 & 10.4 & 13.6 \\
\hline
\end{tabular}

$W R Q T$ is reclaimed wastewater water quality type; $P 3 D S T$ is parameters of $3 \mathrm{D}$ surface topography 
treatment could sustain the growth of microorganisms and bacteria. In this paper, the biofilms thickness attached to laterals during the fast-growth period was tested. There was a unimodal type of relationship between velocity and biofilms thickness. The average thickness of biofilms reached its maximum at velocity $0.45 \mathrm{~m} / \mathrm{s}$. The biofilms surface changed from smooth to rough with the increase in velocity. Under the control velocities of 0.12 and $0.45 \mathrm{~m} / \mathrm{s}$, the surface of biofilms was the roughest and most adhesive.

When the velocity was less than $0.45 \mathrm{~m} / \mathrm{s}$, the solid particulates were easy to deposit and were easily adsorbed or adhered by microorganisms. The biofilms thus grew faster. The growth of biofilms was primarily affected by nutrients and suspended particles transported in laterals. The microorganisms grew slowly because of the limited nutrient supply, and the viscid secretion of EPS was too small to cover or fill the pores among solid granules, which caused a high roughness of the biofilms surface and a large biofilms surface area. It provided good foundation for the growth of biofilms because the chance for the biofilms to adsorb nutrients and capture solid granules increased. With the increase in velocity, the nutrients transport per unit time increased, the nutrients for microorganisms to contact increased, and the growth velocity of microorganisms increased. Generally speaking, under the scope of this velocity, the biofilms were rough, loose, and porous. The inner microorganisms had the access to plenty of nutrients supply. The metabolism was active and there were many flocculent metabolin. The adhesive force of biofilms was stable, and the biofilm was difficult to be detached. At the same time, the flow in the laterals was a laminar flow, the hydraulic shear force was small, and thus, the biofilms thickness increased fast with the increase in velocity.

When the velocity was greater than $0.45 \mathrm{~m} / \mathrm{s}$, the microorganisms contacted more nutrients and solid particles. The nutrients transported by the fluid had satisfied with the requirement for the growth of biofilms, and then, all the pores in the biofilms were fast filled by microorganisms and the viscid secretion of EPS. The biofilms became smooth and the roughness decreased. The biofilms became dense and the pore ratio decreased. The inner microorganisms were blocked for nutrients supply, which caused microorganisms to die. The metabolism became slow and there was little flocculent metabolism. The adhesive force of biofilms deceased, and the biofilm was easy to be detached. At the same time, with the increase in velocity, the turbidity became high and the shear force increased, which caused easier detachment of biofilms. The growth and detachment of biofilms were primarily controlled by hydraulic shear force. Hence, with the increase in velocity, the thickness of biofilms significantly deceased. The biofilms surface topography changed from smooth to rough because the increase in hydrodynamic shear force caused plenty of local detachments and made the surface of biofilms concave. Generally speaking, the reclaimed wastewater by BAF had more nutrients and solid granules than that of FBR. Then, the effects on the growth of biofilms by hydraulic shear force were more significant, and the growth variation of biofilms was higher.

To sum up, the velocity in pipes had significant effects on the growth and topography of biofilms, while the distribution of internal velocity in drip irrigation system was not uniform. The design of main and submain pipes of drip irrigation systems was based on the economic velocity, which was about 2.5-3.0 m/s (Dasberg and Or 1999; Zhang 2007). Hence, the velocity in main and submain pipes was usually large, and the biofilm was difficult to grow. The diameter of laterals was rather small, and the velocity decreased continuously from the front to the back part. It was extremely easy for biofilms to grow and detach from the drip irrigation systems with reclaimed wastewater. The region where the velocity of laterals was about $0.45 \mathrm{~m} / \mathrm{s}$ was the place for biofilms to easily grow. When drip irrigation with reclaimed wastewater was applied, direct connections with regular flushing should be provided in this region of laterals to reduce the growth of biofilms. Though the velocity near the wall of emitter flow path was $0.06-0.5 \mathrm{~m} / \mathrm{s}$, the fluid was turbulent with the continuous disturbance by the complex boundaries (Li et al. 2008). Hence, the hydraulic shear force was strong and it was difficult for biofilms to attach and grow in the emitter flow path. The detachment of biofilms in laterals was hard to deposit in the flow path. The velocity at the inlets of emitter was usually $0.4-0.6 \mathrm{~m} / \mathrm{s}$ (Zhang 2007), the biofilms detached from the laterals was easy to deposit, grow, and re-detach in this region. The velocity in the buffering region of emitter outlets was usually $0.02-0.1 \mathrm{~m} / \mathrm{s}$, and it was easy for biofilms to deposit and grow in this region, but difficult for biofilms to detach. Hence, the deposit usually occurred at the inlets and outlets of emitter and gradually extended to the whole fluid channel. The current research results from domestic and abroad on the distribution of deposits along the emitter flow path also confirmed the results mentioned previously (Cararo et al. 2006; Rowan et al. 2004).

Although several preliminary research results on the effects on the growth and topography of biofilms by the velocity in laterals were achieved in this paper, there are still issues to be solved in the future:

1. The paper was limited to the study on the topography of the biofilms. It is necessary to comprehensively use 
modern molecular biology technologies like polymerase chain reaction-denaturing gradient gel electrophoresis (PCR-DGGE) to analyze the structure of microbial community within the biofilms in laterals and study the dynamic change of the microbial community structure within the laterals' biofilms in the short, medium, and long term.

2. It is necessary to deeply analyze the response characteristics (growth and detachment, topography and structure) of biofilms to the water movement and construct the dynamic growth model of laterals' biofilms under common constraints of hydraulic shear force and nutrients. Moreover, it is necessary to analyze the topography and formation mechanism of laterals' biofilms and focus on the pressure at inlets and pipe length design by controlling the formation of biofilms.

3. The paper is limited to the study on the effects on the biofilms by two types of water quality (BAF and FBR). It is necessary to analyze the effects on the biofilms by various types of water quality and establish indoor simulation drip irrigation systems for analyzing the effects on the growth and detachment of biofilms in laterals by DOM, cations $\left(\mathrm{Ca}^{2+}, \mathrm{Mn}^{2+}, \mathrm{Fe}^{2+}, \mathrm{NH}_{4}{ }^{+}\right.$, etc.), oxides $\left(\mathrm{MnO}_{2}, \mathrm{Fe}_{2} \mathrm{O}_{3}, \mathrm{Al}_{2} \mathrm{O}_{3}, \mathrm{SiO}_{2}\right)$, and anions $\left(\mathrm{HCO}_{3}{ }^{-}, \mathrm{PO}_{4}{ }^{3-}\right.$, and $\left.\mathrm{SO}_{4}{ }^{2-}\right)$ for the sake of revealing the mechanism of clogging in drip irrigation system.

\section{Conclusions}

Three kinds of conclusions were achieved in this paper:

1. The formation of biofilms attached to two reclaimed wastewater drip irrigation laterals went through the process of fast growth, gradual stability, and homeostasis. The growth of biofilms was primarily affected by its components, nutrients transmission within the biofilms, and hydraulic shear force. After the fastgrowth period, the biofilms reached the homeostasis due to the growth-detachment-regrowth cycle.

2. There was a unimodal type of relationship between velocity and thickness of biofilms attached to two reclaimed wastewater laterals during the fast-growth period (72 and $120 \mathrm{~h}$ ). With the increase in velocity, the surface of biofilms went through the process of roughness, smooth, and re-roughness. The average thickness, roughness, and adhesive ability of biofilms reached maximum values at velocity $0.45 \mathrm{~m} / \mathrm{s}$, a critical velocity. The formation of biofilms in laterals was primarily dominated by nutrients and suspended particles for velocities less than the critical velocity, whereas it was primarily controlled by hydraulic shear force for velocities greater than the critical velocity.

3. Analyzing from the aspect of flow velocity distribution and hydraulic shear stress characteristics in pipes and emitters of drip irrigation system, the emitter clogging was related to the growth and detachment of biofilms in laterals. The biofilms detached from the laterals, which accumulated and grew at inlets and outlets of emitter. That is the primary factor to induce the emitter clogging.

Acknowledgments We are grateful for the financial support from the National Natural Science Fund of China (NSFC) (No. 50379053 and 50779068) and support by the Program for Changjiang Scholars and Innovative Research Team in University (PCSIRT) (No. IRT0657). We would like to thank the State Key Laboratory of Tribology in Tsinghua University for providing the vertical scanning white-light interference profilometer.

\section{References}

Adin A, Sacks M (1991) Drip-clogging factors in wastewater irrigation. J Irrig Drain ASCE 117(6):813-826

Asano T, Burton F, Leverenz H, Tsuchihashi R, Tchobanoglous G (2007) Water reuse: issues, technologies and applications. McGraw-Hill Professional Publishing, New York

Avnimelech Y (1993) Irrigation with effluents: the Israeli experience. Environ Sci Tech 27(7):1278-1281

Bakke R, Trulear MG, Robinson JA, Characklis WG (1984) Activity of pseudomonas aeruginosa in steady-state biofilms. Biotech Bioeng 26(11):1418-1424

Bishop PL (2007) The role of biofilms in water reclamation and reuse. Water Sci Tech 55:19-26

Capra A, Scicolone B (2004) Emitter and filter tests for wastewater reuse by drip irrigation. Agr Water Manage 68:135-149

Capra A, Scicolone B (2005) Assessing dripper clogging and filtering performance using municipal wastewater. Irrig Drain 54:71-79

Cararo DC, Botrel TA, Hills DJ, Leverenz HL (2006) Analysis of clogging in drip emitters during wastewater irrigation. Appl Eng Agri 22(2):251-257

Chang HT, Rittmann BE, Amar D, Heim R, Ehlinger O, Lesty Y (1991) Biofilm detachment mechanisms in a liquid fluidized bed. Biotech Bioeng 38(5):499-506

Chen S (2007) Characteristics and efficiency investigation of suspended carrier biofilm for treating highly concentrated organic wastewater. $\mathrm{PhD}$ thesis, Harbin Institute of Technology

Cloete TE, Westaard D, Van SJ (2003) Dynamic response of biofilm to pipe surface and fluid velocity. Water Sci Tech 47(5):57-59

Dasberg S, Or D (1999) Drip irrigation. Springer, Berlin

Gouidera M, Bouzida J, Sayadi S, Montiel A (2009) Impact of orthophosphate addition on biofilm development in drinking water distribution systems. J Hazard Mater 167:1198-1202

Horn H, Rciff H, Morgenroth E (2003) Simulation of growth and detachment in biofilm systems under defined hydrodynamic conditions. Biotech Bioeng 81(5):607-617

Lehtola MJ, Laxander M, Miettinen IT, Hirvonen A, Vartiainen T, Martikainen PJ (2006) The effects of changing water flow velocity on the formation of biofilms and water quality in pilot distribution system consisting of copper or polyethylene pipes. Water Res 40(11):2151-2160 
Li YK, Yang PL, Ren SM, Xu TW (2006) Hydraulic characterizations of tortuous labyrinth path drip irrigation emitter. J Hydrodynamics Ser B 18(4):449-457

Li YK, Yang PL, Xu TW, Ren SM, Lin XC, Xu FP (2008) CFD and digital particle tracking to assess flow characteristics in the labyrinth path of a drip irrigation emitter. Irri Sci 26:427-438

Li YK, Li GB, Liu YZ, Xu TW, Liu HS, Ren SM, Yan DZ, Yang PL (2010) Surface topographic characteristics of suspended particulates in reclaimed wastewater and effects on clogging in labyrinth drip irrigation emitters. Irri Sci (submitted)

Liu HJ, Huang GH (2009) Laboratory experiment on drip emitter clogging with fresh water and treated sewage effluent. Agr Water Manage 96:745-756

Manuel CM, Nunes OC, Melo LF (2007) Dynamics of drinking water biofilm in flow/non-flow conditions. Water Res 41:551-562

Nicolella C, Felice RD, Rovatti M (1996) An experimental method of biofilm detachment in liquid bed biological reactors. Biotech Bioeng 51(6):713-719

Ollos PJ (1998) Effects of drinking water biodegradability and disinfectant residual on bacterial regrowth ( $\mathrm{PhD}$ thesis). Waterloo University, Ontario

Percival SL, Knapp JS, Wales DS, Edyvean RGJ (2001) Metal and inorganic ion accumulation in biofilms exposed to flowing and stagnant water. Brit Corros J 36:105-110
Qin SY (2008) Study on morphology and biodiversity of biofilm of river Oder. $\mathrm{PhD}$ thesis, Harbin Institute of Technology, Harbin (in Chinese)

Ravina I, Paz E, Sofer Z, Marcu A, Shisha A, Sagi G (1992) Control of emitter clogging in drip irrigation with reclaimed wastewater. Irri Sci 13(3):129-139

Ravina I, Paz E, Sofer Z, Marm A, Schischa A, Sagi G, Yechialy Z, Lev Y (1997) Control of clogging in drip irrigation with stored treated municipal sewage effluent. Agr Water Manage 33(2):127-137

Rittmann BE (1982) The effect of shear stress on biofilm loss rate. Biotech Bioeng 24(2):501-506

Rowan MA, Mancl K, Tuovinen OH (2004) Clogging incidence of drip irrigation emitters distributing effluents of differing levels of treatment. In: Mankin KR (ed) On-site wastewater treatment X, conference proceedings/ASAE publication number 701P0104, pp 84-91

Simpson RD (2008) Biofilm processes in biologically active carbon water purification. Water Res 42:2839-2848

Yan DZ, Bai ZH, Rowan MA, Ren SM, Yang PL (2009) Biofilm structure and its influence on clogging in drip irrigation emitters distributing reclaimed wastewater. J Enviro Sci 21(6):834-841

Zhang ZX (2007) Principles and applications of drip irrigation system. China Waterpower Press, Beijing (in Chinese) 